\title{
Phase boundary engineering of metal-organic-framework-derived carbonaceous nickel selenides for sodium-ion batteries
}

\author{
Shiyao Lu ${ }^{1,4,}, \mathrm{Hu} \mathrm{Wu}^{1, \S}$, Jingwei Hou ${ }^{2,7}$, Limin Liu', Jiao Li ${ }^{1}$, Chris J. Harris², Cheng-Yen Lao ${ }^{2}$, Yuzheng Guo ${ }^{5}$, \\ Kai Xi ${ }^{2,3}(\bowtie)$, Shujiang Ding ${ }^{1}(\bowtie)$, Guoxin Gao ${ }^{1}(\bowtie)$, Anthony K. Cheetham ${ }^{2,6}$, and R. Vasant Kumar ${ }^{2}$ \\ ${ }^{1}$ Xi'an Key Laboratory of Sustainable Energy Materials Chemistry, MOE Key Laboratory for Nonequilibrium Synthesis and Modulation of \\ Condensed Matter, State Key Laboratory of Electrical Insulation and Power Equipment, School of Chemistry, Xian Jiaotong University \& Shaanxi \\ Quantong Joint Research Institute of New Energy Vehicles Power, Xian Jiaotong University, Xian 710049, China \\ ${ }^{2}$ Department of Materials Science and Metallurgy, University of Cambridge, Cambridge CB3 OFS, UK \\ ${ }^{3}$ Cambridge Graphene Centre, Department of Engineering, University of Cambridge, Cambridge CB3 OFA, UK \\ ${ }^{4}$ Department of Chemistry, City University of Hong Kong, Hong Kong 999077, Hong Kong, China \\ ${ }^{5}$ School of Electrical Engineering and Automation, Wuhan University, Wuhan 430072, China \\ ${ }^{6}$ Materials Research Laboratory, University of California, Santa Barbara, CA 93106, USA \\ ${ }^{7}$ School of Chemical Engineering, University of Queensland, St Lucia, QLD 4072, Australia \\ ${ }^{\S}$ Shiyao Lu and $\mathrm{Hu}$ Wu contributed equally to this work.
}

(C) The Author(s) 2020

Received: 16 March 2020 / Revised: 23 April 2020 / Accepted: 30 April 2020

\begin{abstract}
Sodium-ion batteries (SIBs) are promising power sources due to the low cost and abundance of battery-grade sodium resources, while practical SIBs suffer from intrinsically sluggish diffusion kinetics and severe volume changes of electrode materials. Metalorganic framework (MOFs) derived carbonaceous metal compound offer promising applications in electrode materials due to their tailorable composition, nanostructure, chemical and physical properties. Here, we fabricated hierarchical MOF-derived carbonaceous nickel selenides with bi-phase composition for enhanced sodium storage capability. As MOF formation time increases, the pyrolyzed and selenized products gradually transform from a single-phase $\mathrm{Ni}_{3} \mathrm{Se}_{4}$ into bi-phase $\mathrm{NiSe}_{x}$ then single-phase $\mathrm{NiSe}_{2}$, with concomitant morphological evolution from solid spheres into hierarchical urchin-like yolk-shell structures. As SIBs anodes, bi-phase $\mathrm{NiSe}_{x} @ \mathrm{C} / \mathrm{CNT}-10 \mathrm{~h}$ (10 h of hydrothermal synthesis time) exhibits a high specific capacity of $387.1 \mathrm{mAh} / \mathrm{g}$ at $0.1 \mathrm{~A} / \mathrm{g}$, long cycling stability of $306.3 \mathrm{mAh} / \mathrm{g}$ at a moderately high current density of $1 \mathrm{~A} / \mathrm{g}$ after 2,000 cycles. Computational simulation further proves the lattice mismatch at the phase boundary facilitates more interstitial space for sodium storage. Our understanding of the phase boundary engineering of transformed MOFs and their morphological evolution is conducive to fabricate novel composites/hybrids for applications in batteries, catalysis, sensors, and environmental remediation.
\end{abstract}

\section{KEYWORDS}

metal organic frameworks, phase boundary, carbon nanotube, metal selenides, sodium ion batteries

\section{Introduction}

Rechargeable sodium-ion batteries (SIBs) are regarded as potential power sources for large-scale energy storage devices due to the low cost and abundance of sodium resources [1-4]. However, the large radius of the $\mathrm{Na}^{+}$ion $(0.98 \AA$ compared with $0.69 \AA$ for $\mathrm{Li}^{+}$) accounts for its intrinsically sluggish diffusion kinetics and severe volume changes, usually leading to unimpressive electrochemical performance $[5,6]$. On account of these factors, numerous efforts have been devoted to developing stable electrodes in order to achieve good sodium storage ability. Among the various anode candidates, transitional metal sulfides [7-13], which store sodium via a conversion or alloy-dealloying reaction mechanisms, stand out for their impressive electronic conductivity and substantial theoretical capacity compared to hard carbon anodes (typically less than $300 \mathrm{mAh} / \mathrm{g}$ ) [1, 14]. However, a "shuttle effect" generated by dissolution and diffusion of polysulfide ions occurs for most metal sulfides, leading to rapid capacity fading and poor cycle stability [15-17]. Compared to metal sulfides, metal selenides usually exhibit higher electronic conductivity and structural stability, and can thus present an improved cycle life and high rate performance with appropriate electrolytes operating within selected voltage window [18-20]. For example, Zhang and co-workers fabricated $\mathrm{FeSe}_{2}$ cluster anodes which achieved 400 cycles at $1 \mathrm{~A} / \mathrm{g}$ [21]. However, dramatic volume variations and severe aggregation still took place during long-term cycling, leading to undesirable cycle performance for the metal selenides.

In order to stabilize the structures, avoid agglomeration and further enhance the conductivity of metal selenides-based anodes, one efficient strategy that has been frequently adopted is to fabricate carbonaceous composites with porous morphologies by hybridizing electroactive metal chalcogenides with carbon matrixes, such as hollow carbon spheres, graphene and carbon nanotubes (CNTs) [22-27]. Wu et al. proposed

Address correspondence to Kai Xi, kx210@cam.ac.uk; Shujiang Ding, dingsj@xjtu.edu.cn; Guoxin Gao, gaoguoxin@mail.xjtu.edu.cn 
an epitaxial growth strategy to obtain hierarchical porous CoSe-rGO hybrids with enhanced mechanical strength while suppressing the dissolution of Se [28]. Confining electroactive materials within a conductive carbon matrix can significantly enhance structural stability and shorten $\mathrm{Na}^{+}$ion diffusion lengths during repeated charge-discharging cycling. Moreover, this strategy maintains their original morphology after continuous cycling, resulting in enhanced capacity and cycling stability $[29,30]$. In a related development, it has been found that metal-organic frameworks (MOFs) can be efficiently converted [31-34], by means of a facile calcination or pyrolysis treatment, into nanostructured carbonaceous metal chalcogenide composites, which have exhibited excellent electrochemical properties in lithium-ion batteries (LIBs), SIBs and Li-S batteries [35-42]. This is because the carbonized and graphitized carbon generated by in situ calcination encapsulates the electroactive material, significantly alleviating the volume expansion during repeated sodiation/desodiation whilst simultaneously proving good electronic conductivity [43]. Recent work has shown that the carbonization of MOFs can be sensitive to both their morphology and the pyrolysis reaction conditions. For example, the morphology of MOFs can be tuned by using different synthesis conditions such as temperature, time, ligands and the ratios of reactants [44, 45]. Adjusting such reaction parameters has been used to maximize the porosity of MOFs, leading to enhanced energy storage capability. In addition, other recent research indicates that carbonizing MOFs by a low temperature pyrolysis process using reducing gas enables a two-step reaction: First, metal nanocatalysts are generated from internal metal ions, and second, CNTs are produced from residual organic units [46]. By employing this method, a series of MOF-derived CNT-assembled composites with different morphologies could be fabricated with hierarchical pores and high specific surface area. A further selenization step on the product can turn the carbonized MOF into CNTconfined metal selenides that have high capacities that can be exploited in energy storage. For example, Qiu's group successfully prepared CNT-bridged carbon $\mathrm{CoSe}_{2}$ nanospheres, which delivered a high reversible capacity of $470 \mathrm{mAh} / \mathrm{g}$ at $0.2 \mathrm{~A} / \mathrm{g}$ [41]. This work elucidated the importance of developing metal selenide composites with interior void space and a conductive network for high-performance sodium electrode materials. In addition, biphasic selenides exhibit higher electronic conductivities and richer redox reactions when compared to monophasic selenides, which can further improve the electrochemical performance [47].

Herein, we systematically study the morphological evolution of Ni-BTC MOF (BTC = benzenetricarboxylic acid) and their transformed nanostructures for energy storage applications [46]. As the hydrothermal synthesis time was gradually increased from 3 to $15 \mathrm{~h}$, the Ni-BTC MOFs (denoted as Ni-MOF-3h, Ni-MOF-5h, Ni-MOF-10h and Ni-MOF-15h, respectively) grow from solid spheres into hollow urchin-like shapes. Subsequent low temperature pyrolysis then transforms the Ni-MOF samples into carbon-confined metallic $\mathrm{Ni}$ nanoparticles, which further catalyzes the in-situ formation of extruded CNTs from the 5, 10,15h Ni-BTC samples (denoted as Ni@C-3h, Ni@C/CNTs-5h, $\mathrm{Ni@C/CNTs-10h,} \mathrm{Ni@C/CNTs-15h,} \mathrm{respectively).} \mathrm{After} \mathrm{a} \mathrm{simple}$ selenization process, solid Ni@C-3h samples are transformed into a $\mathrm{Ni}_{3} \mathrm{Se}_{4}$ phase, while Ni@C/CNTs-15h converts into a $\mathrm{NiSe}_{2}$ phase. As the carbonization time of the Ni-BTC samples increases, the final selenized products gradually transform from $\mathrm{Ni}_{3} \mathrm{Se}_{4}$ into $\mathrm{NiSe}_{2}$ (denoted as $\mathrm{Ni}_{3} \mathrm{Se}_{4} @ \mathrm{C}-3 \mathrm{~h}, \mathrm{NiSe}_{x} @ \mathrm{C} / \mathrm{CNTs}-5 \mathrm{~h}$, $\mathrm{NiSe}_{x} @ \mathrm{C} / \mathrm{CNTs}-10 \mathrm{~h}, \mathrm{NiSe}_{2} @ \mathrm{C} / \mathrm{CNTs}-15 \mathrm{~h}$, respectively). The nanocomposites with highly active phase boundary exhibit excellent performance as anodes in sodium batteries: for example, NiSe $@$ C/CNT-10h provides a high reversible capacity $(387.1 \mathrm{mAh} / \mathrm{g}$ at $100 \mathrm{~mA} / \mathrm{g}$ ) and ultralong cycling performance $306.3 \mathrm{mAh} / \mathrm{g}$ at $1 \mathrm{~A} / \mathrm{g}$ after 2,000 cycles). Further exploration of this morphological evolution will allow the development of new classes of hybrid materials with hierarchical nanostructures for applications in batteries, sensors and catalysts.

\section{Results and discussion}

Figure 1 presents the schematic diagram of the morphology evolution of the Ni-BTC MOFs with reaction time and the corresponding synthesis of nickel selenide/carbon composites. Initially, Ni-BTC MOFs were fabricated through a hydrothermal reaction with a mixture of nickel nitrate, trimesic acid and polyvinylpyrrolidone (PVP) (acting as a metal source, organic ligand and stabilizing agent, respectively) [44]. The reaction

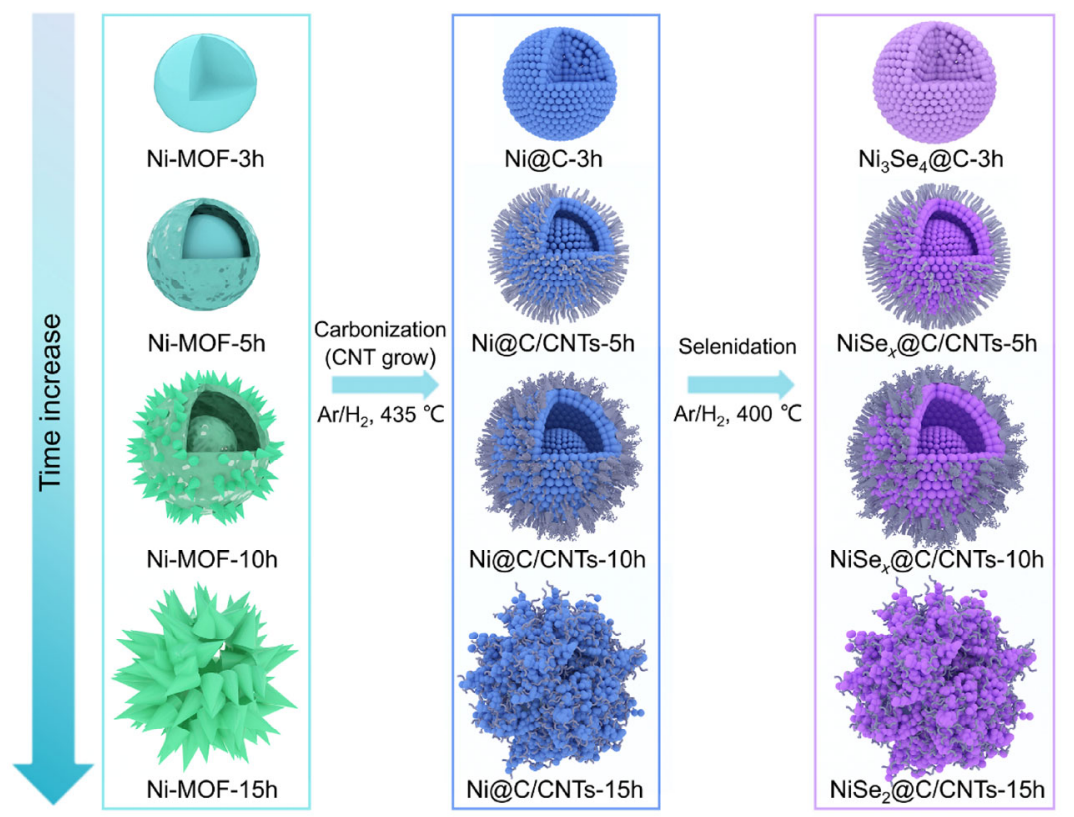

Figure 1 Schematic illustrations for the evolution of Ni-MOF in different hours and strategy for fabricating nickel selenides/carbon composites used as anode materials for SIBs. 
time was precisely regulated from 3 to $15 \mathrm{~h}$ to understand the evolution of this process. The morphological evolution of Ni-BTC MOFs with time was first characterized by field emission scanning electron microscopy (FESEM) and transmission electron microscopy (TEM). As shown in Figs. 2(a)-2(h), both Ni-MOF-3h and Ni-MOF-5h samples have a spherical structure with diameters in the range of 1.2 to $1.6 \mu \mathrm{m}$. Ni-MOF-5h samples, however, exhibit an inconspicuous hollow structure and a rough surface in comparison to the solid $\mathrm{Ni}-\mathrm{MOF}-3 \mathrm{~h}$ samples. As the reaction time extends to $10 \mathrm{~h}$, a typical Ostwald ripening process, which leads to a hierarchical core-shell structure with staggered nanorods emerging from its external shell, is observed [48]. The nanorods continue to grow as the reaction time increases. After $15 \mathrm{~h}$, the Ni-MOF-15h samples transform into an urchin-like structure, whilst some nanorods collapse, indicating the instability of the samples. X-ray diffraction (XRD) analysis of the above samples demonstrated that the Ni-BTC MOFs gradually transform from amorphous to crystalline materials during the solvothermal reactions (Fig. S1 in the Electronic Supplementary Material (ESM)).

Subsequently, the Ni-BTC MOFs were annealed under $\mathrm{Ar} / \mathrm{H}_{2}$ flow at $435^{\circ} \mathrm{C}$ for $8 \mathrm{~h}$ to obtain CNTs-connected carboncoated nickel nanospheres. The pyrolyzed MOFs reveal two distinct morphologies (Figs. 2(i)-2(l) and Fig. S2 in the ESM). For the solid Ni@C-3h sample, the Ni-MOF-3h is reduced into numerous graphitic carbon-enclosed nickel nanoparticles with diameters in the range of 5-30 nm. For the rest of the samples, we succeed in inducing the residual organics from the external shell and nanorods to form oriented CNT structures containing nickel nanoparticles. These CNTs possess outer diameters ranging from 15 to $20 \mathrm{~nm}$, in which crystalline nickel nanoparticles are encapsulated. It is also observed that some of the shell structure in the Ni@C/CNTs-15h sample almost detached from the main body, generating clusters of CNTs attached to the inner core. The XRD analysis and the energy dispersive X-ray (EDX) spectroscopy results of the above four samples demonstrate the existence of metallic nickel and graphite (Figs. S3 and S4 in the ESM). In particular, the surface carbon ratios in the four samples reveal increasing concentrations, which is attributed to the increasing CNT content.

Lastly, the Ni@C and Ni@C/CNT composites were selenized by a post-pyrolysis process under an $\mathrm{H}_{2} \mathrm{Se}$ airflow generated from the reaction of $\mathrm{H}_{2}$ and Se powders, resulting in $\mathrm{Ni}_{3} \mathrm{Se}_{4} @ \mathrm{C}$ and NiSe $e_{x} @ \mathrm{C} / \mathrm{CNTs}$ composites [41]. The corresponding TEM and FESEM images are illustrated in Figs. 3(a)-3(h), which show that the samples almost maintain their former morphologies. Furthermore, elemental mapping images (Figs. 3(i)-3(l)) performed on the high-angle annular dark field, scanning transmission electron microscopy (HADDF-STEM) confirmed the uniform elemental distributions in all four samples, implying a complete selenization process. In addition, EDX spectroscopy results (Fig. S5 in the ESM) of the selenized samples detected $\mathrm{Ni}, \mathrm{Se}$ and $\mathrm{C}$ elements in the hybrid structures. Notably, the atomic ratio of $\mathrm{C}$ to Se increases gradually, indicating inconsistent element contents across the four samples.

To verify the specific crystallinity of the four composites, XRD analysis was performed (Fig. 4(a)). Interestingly, selenization is not uniform across the four samples; that is to say, both wilkmanite $\mathrm{Ni}_{3} \mathrm{Se}_{4}$ (JCPDS card no.18-0890) and penroseite $\mathrm{NiSe}_{2}$ (JCPDS card no.88-1711) are detected as the main components [49]. The selenization process of the solid

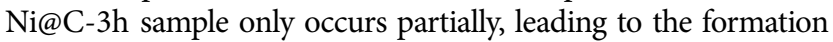
of a lower Se content $\mathrm{Ni}_{3} \mathrm{Se}_{4} @ \mathrm{C}-3 \mathrm{~h}$ composite, in contrast to the other samples which are dominated by $\mathrm{NiSe}_{2}$. As the hydrothermal reaction time increases, the predominant peak at $45.1^{\circ}$ (corresponding to the (114) reflection) from $\mathrm{Ni}_{3} \mathrm{Se}_{4}$ decreases gradually, which is associated with the appearance of characteristic $\mathrm{NiSe}_{2}$ peaks at $29.8^{\circ}$ and $36.6^{\circ}$ (corresponding to the (220) and (221) reflections). More specifically, the XRD patterns and crystal structures of $\mathrm{NiSe}_{2}$ and $\mathrm{Ni}_{3} \mathrm{Se}_{4}$ are displayed in Fig. S6 in the ESM, separately. We conclude from the XRD results that the 5 and $10 \mathrm{~h}$ samples contain both $\mathrm{Ni}_{3} \mathrm{Se}_{4}$ and $\mathrm{NiSe}_{2}$, and that the $15 \mathrm{~h}$ samples contain almost pure $\mathrm{NiSe}_{2}$ with trace $\mathrm{Ni}_{3} \mathrm{Se}_{4}$. They are denoted as $\mathrm{NiSe}_{x} @ \mathrm{C} / \mathrm{CNTs}-$ 5h, NiSe $e_{x}$ C/CNTs-10h and NiSe ${ }_{2} @$ C/CNTs-15, respectively. Furthermore, the crystal structures of $\mathrm{Ni}_{3} \mathrm{Se}_{4} @ \mathrm{C}-3 \mathrm{~h}$ and $\mathrm{NiSe}_{x} @ \mathrm{C} /$ CNTs-10h were also studied by high-resolution TEM (HRTEM) and selected area electron diffraction (SAED) analysis. As shown in Figs. 4(d)-4(h), the sizes of the $\mathrm{Ni}_{3} \mathrm{Se}_{4}$ nanoparticles are in the range of 20-50 nm with several graphitic carbon layers, while the CNT-bridged $\mathrm{NiSe}_{x}$ nanoparticles reveal a smaller size of $10-45 \mathrm{~nm}$. An interplanar distance of 0.202 and $0.269 \mathrm{~nm}$ are detected in $\mathrm{Ni}_{3} \mathrm{Se}_{4} @ \mathrm{C}-3 \mathrm{~h}$ and $\mathrm{NiSe}_{x} @ \mathrm{C} / \mathrm{CNTs}-10 \mathrm{~h}$ samples, corresponding to the dominant (114) and (210) planes of $\mathrm{Ni}_{3} \mathrm{Se}_{4}$ and $\mathrm{NiSe}_{2}$, respectively. Furthermore, a phase boundary can be observed between (211) facet of $\mathrm{NiSe}_{2}$ and (114) facet of

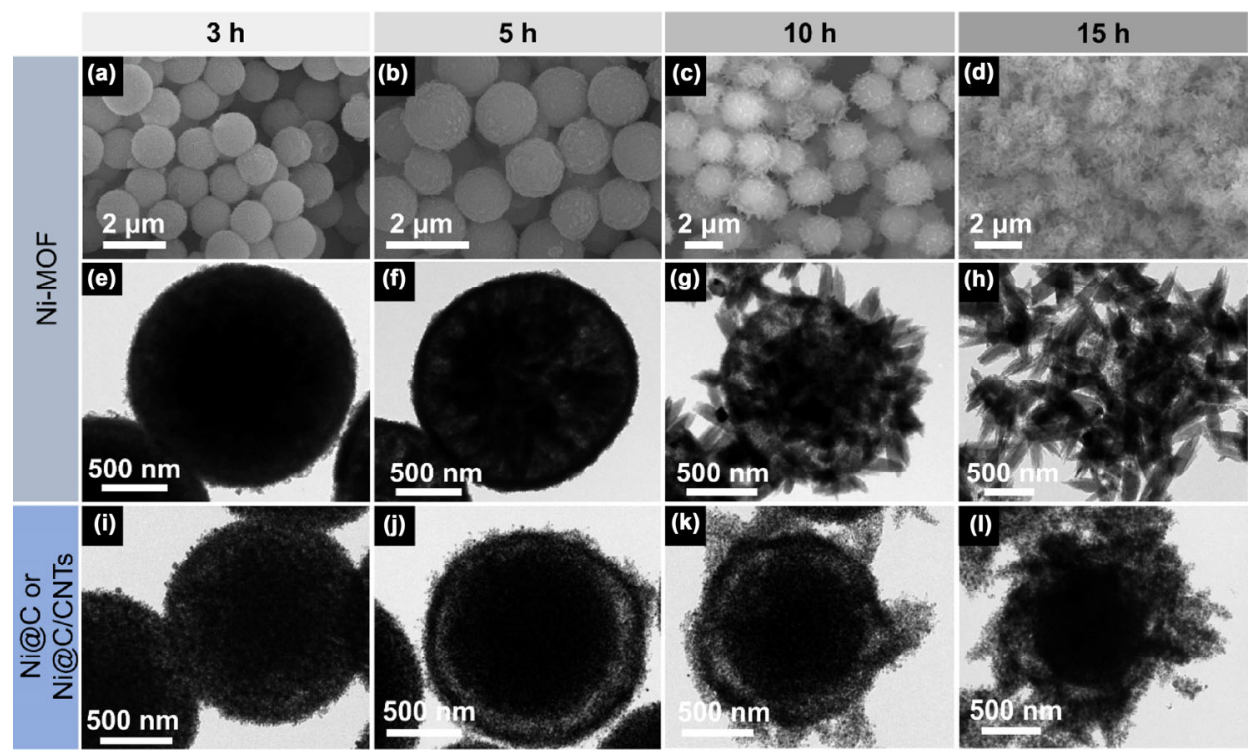

Figure 2 FESEM and TEM images of ((a) and (e)) Ni-MOF-3h; ((b) and (f)) Ni-MOF-5h; ((c) and (g)) Ni-MOF-10h; ((d) and (h)) Ni-MOF-15h. TEM images of (i) Ni@C-3h; (j) Ni@C/CNTs-5h; (k) Ni@C/CNTs-10h; (l) Ni@C/CNTs-15h. 

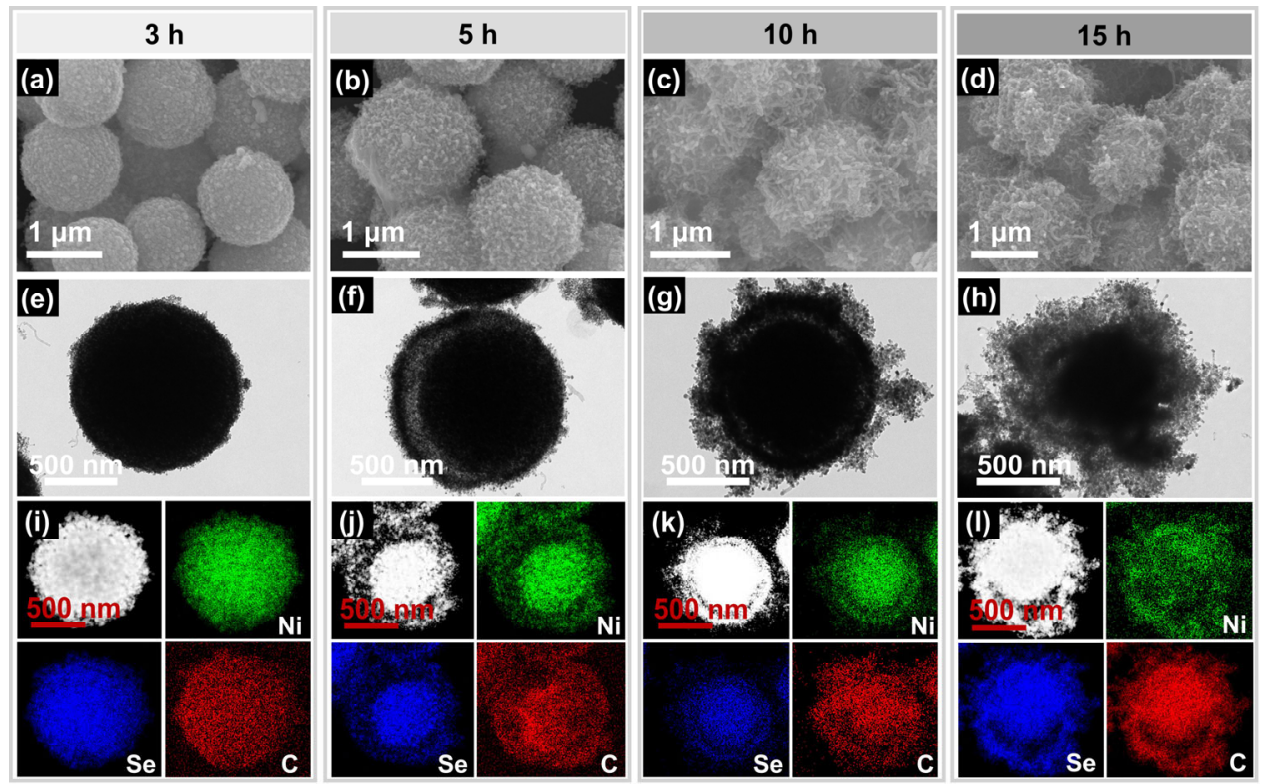

Figure 3 FESEM, TEM, HAADF-STEM and corresponding elemental mapping images of ((a), (e) and (i)) $\mathrm{Ni}_{3} \mathrm{Se}_{4} @ \mathrm{C}-3 \mathrm{~h}$; ((b), (f) and (j)) NiSe $e_{x} \mathrm{C} / \mathrm{CNTs}-5 \mathrm{~h}$; ((c), (g) and (k)) NiSe $e_{x}$ C/CNTs-10h; ((d), (h) and (l)) NiSe $e_{2}$ C/CNTs-15h.
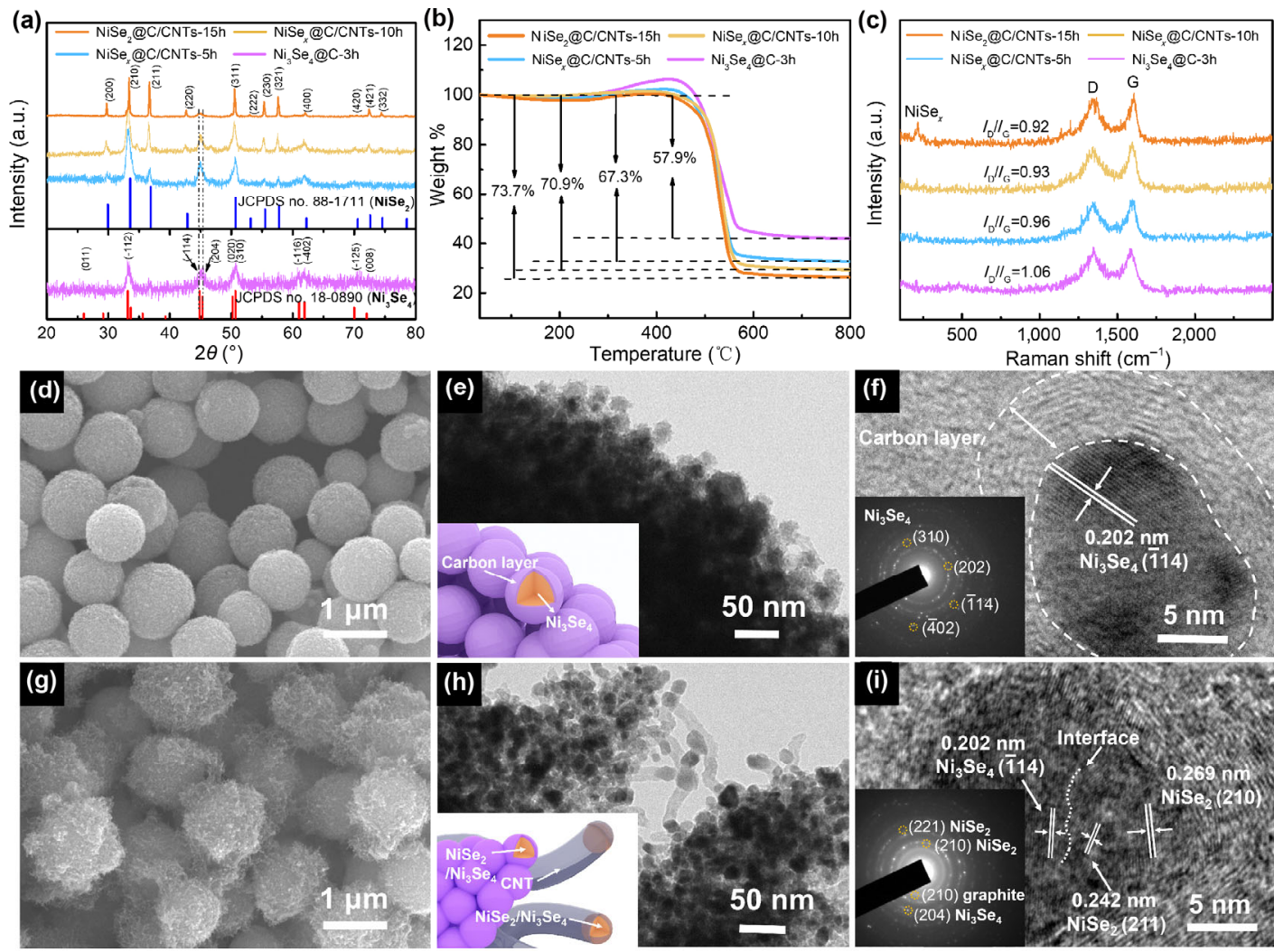

Figure 4 Characterization of various nickel selenides/carbon composites. ((a)-(c)) XRD patterns, TGA curves and Raman spectra of Nis $e_{4} @ \mathrm{C}-3 \mathrm{~h}$, $\mathrm{NiSe}_{x} @ \mathrm{C} / \mathrm{CNTs}-5 \mathrm{~h}, \mathrm{NiSe}_{x} @ \mathrm{C} / \mathrm{CNTs}-10 \mathrm{~h}, \mathrm{NiSe}_{2} @ \mathrm{C} / \mathrm{CNTs}-15 \mathrm{~h} ;$ SEM, TEM, HRTEM and SAED images of ((d)-(f)) Ni $\mathrm{Ne}_{4} @ \mathrm{C}-3 \mathrm{~h},((\mathrm{~g})-(\mathrm{i}))$ NiSe $@ \mathrm{C} / \mathrm{CNTs}-10 \mathrm{~h}$.

$\mathrm{Ni}_{3} \mathrm{Se}_{4}$, demonstrating a lattice mismatch between two phases. The SAED patterns of two samples also reveal a polycrystalline feature and the intense diffraction rings are readily indexed as monoclinic $\mathrm{Ni}_{3} \mathrm{Se}_{4}$ and cubic $\mathrm{NiSe}_{2}$, which is in a good agreement with the XRD results.

The total carbon content in the four composites was determined by thermogravimetric analysis (TGA). As displayed in Fig. 4(b), the TGA curves first display a weight loss due to the loss of water from 25 to $200{ }^{\circ} \mathrm{C}$. The weight gain that follows, between 200 to $432{ }^{\circ} \mathrm{C}$, can be credited to the oxidation of $\mathrm{Ni}_{3} \mathrm{Se}_{4}$ and $\mathrm{NiSe}_{2}$, generating $\mathrm{NiO}$ and $\mathrm{SeO}_{2}$. An abrupt weight loss emerges once the temperature is over $\sim 430{ }^{\circ} \mathrm{C}$, which is due to the volatilization of $\mathrm{SeO}_{2}$ and the generation of $\mathrm{CO}_{2}$. The total reaction is summarized as: $\mathrm{Ni}_{x} \mathrm{Se} @ \mathrm{C}+\mathrm{O}_{2} \rightarrow x \mathrm{NiO}+$ $\mathrm{SeO}_{2} \uparrow+\mathrm{CO}_{2} \uparrow$ [43]. We assume that $\mathrm{Ni}_{3} \mathrm{Se}_{4} @ \mathrm{C}-3 \mathrm{~h}$ and $\mathrm{NiSe}_{2} @ \mathrm{C} /$ CNTs-15h are pristine $\mathrm{Ni}_{3} \mathrm{Se}_{4} @ \mathrm{C}$ and $\mathrm{NiSe}_{2} @ \mathrm{C}$ composites, respectively, and that the other samples are $\mathrm{Ni}_{3} \mathrm{Se}_{4} @ \mathrm{NiSe}_{2} @ \mathrm{C}$ hybrid composites. Therefore, the carbon content in the four samples can be approximately estimated as being between $7.6 \%$ and $23.8 \%$, revealing an increasing carbon content from $\mathrm{Ni}_{3} \mathrm{Se}_{4} @ \mathrm{C}-3 \mathrm{~h}$ to $\mathrm{NiSe}_{2} @ \mathrm{C} / \mathrm{CNTs}-15 \mathrm{~h}$. Figure 4(c) gives the Raman spectra of the four composites. The minor peak 
at $208.3 \mathrm{~cm}^{-1}$ is ascribed to the $\mathrm{Ag}_{\mathrm{g}}$ mode of $\mathrm{Ni}_{x} \mathrm{Se}$ [49]. Two additional peaks emerge at 1,348.7 (D band) and 1,601.5 $\mathrm{cm}^{-1}$ ( $G$ band), which are associated with disordered carbon and graphitic carbon, respectively. Remarkably, The $I_{\mathrm{D}} / I_{\mathrm{G}}$ ratio decreases from 1.06 to 0.92 across the four samples, demonstrating the existence of graphitic carbon grown from CNTs.

In order to further understand the differences in chemical composition and valence states between $\mathrm{Ni}_{3} \mathrm{Se}_{4}$ and $\mathrm{NiSe}_{2}$, $\mathrm{X}$-ray photoelectron spectroscopy (XPS) was conducted on the $\mathrm{Ni}_{3} \mathrm{Se}_{4} @ \mathrm{C}-3 \mathrm{~h}$ and $\mathrm{NiSe}_{2} @ \mathrm{C} / \mathrm{CNTs}-15 \mathrm{~h}$ samples and their Se 3d spectra are shown in Fig. S7 in the ESM. In general, four main peaks at 54.3, 55.0, 55.6 and $59.2 \mathrm{eV}$ can be deconvoluted in both samples, corresponding to Se $3 d_{5 / 2}$, Se $3 d_{3 / 2}$, Se-Se and $\mathrm{Se}-\mathrm{O}$, respectively. However, the $\mathrm{Ni}_{3} \mathrm{Se}_{4} @ \mathrm{C}-3 \mathrm{~h}$ samples reveal enhanced Se $3 d_{5 / 2}$ and decreased Se-Se peak intensity compared with $\mathrm{NiSe}_{2} @ \mathrm{C} / \mathrm{CNTs}-15 \mathrm{~h}$ samples, which could be ascribed to the greater weighting from the Se-Se bond in $\mathrm{NiSe}_{2}$. The porosities and pore size distributions of the as-prepared hybrid composites were estimated by Brunauer-Emmert-Teller (BET) analysis. As shown in Fig. S8 in the ESM, the distinct hysteresis loops between the adsorption and desorption curves imply the presence of porous structure within all samples. The solid $\mathrm{Ni}_{3} \mathrm{Se}_{4} @ \mathrm{C}-3 \mathrm{~h}$ sample presents the lowest surface area of $64.1 \mathrm{~m}^{2} / \mathrm{g}$ with an average pore size at $32.3 \mathrm{~nm}$. As the samples change from a solid structure to a hollow CNT-bridged structure, an enlarged surface area and decreased pore size are obtained. Thus, the NiSe $\mathrm{N}_{2} @ \mathrm{C} / \mathrm{CNTs}$-15h sample exhibits the largest surface area of $108.1 \mathrm{~m}^{2} / \mathrm{g}$ with an average pore size at $8.6 \mathrm{~nm}$.

The electrochemical performances of the four nickel selenide composites for SIBs were evaluated by assembling them into coin-type half-cells. In accordance with previous reports, the voltage window was modified to $0.5-2.9 \mathrm{~V}$ in order to avoid side reactions [50]. Figure S9 in the ESM displays the cycling performance of the four samples at a current density of $1 \mathrm{~A} / \mathrm{g}$. All four samples reveal excellent cycling stability with differing specific capacities. We therefore performed rate performance measurements on the nickel selenide nanocomposites, as displayed in Fig. 5(a). As with the results of the cycling performance, NiSe $\mathrm{N}_{x} @ \mathrm{C} / \mathrm{CNTs}-10$ possesses the best rate performance among the four samples. The specific capacities of $\mathrm{NiSe}_{2} @ \mathrm{C} /$ CNTs-15 and NiSe $e_{x} @ \mathrm{C} / \mathrm{CNTs}-5 \mathrm{~h}$ are slightly lower than that of $\mathrm{NiSe}_{x} @ \mathrm{C} / \mathrm{CNTs}-10 \mathrm{~h}$, while $\mathrm{Ni}_{3} \mathrm{Se}_{4} @ \mathrm{C}-3 \mathrm{~h}$ has the lowest specific capacity. As the current density increases from 0.1 to 0.2 , $0.5,1.0,2.0,5.0$ and $10.0 \mathrm{~A} / \mathrm{g}$, the reversible discharge capacity of $\mathrm{NiSe}_{x} @ \mathrm{C} / \mathrm{CNTs}-10 \mathrm{~h}$ gradually changes from 387.1 to 357.8 , $334.5,321.2,306.6,282.7$ and $258.4 \mathrm{mAh} / \mathrm{g}$, respectively. When it is reset to $1 \mathrm{~A} / \mathrm{g}$ after 70 cycles, the discharge capacity rapidly recovers to $322.5 \mathrm{mAh} / \mathrm{g}$, indicating the superb high-rate performance of $\mathrm{NiSe}_{x} @ \mathrm{C} / \mathrm{CNTs}-10$. However, the discharge capacity of $\mathrm{Ni}_{3} \mathrm{Se}_{4} @ \mathrm{C}-3$ was only 283.7 and $99.8 \mathrm{mAh} / \mathrm{g}$ at 0.1 and $10 \mathrm{~A} / \mathrm{g}$, respectively. Such behavior can be ascribed to the different phase contents of $\mathrm{Ni}_{3} \mathrm{Se}_{4}, \mathrm{NiSe}_{2}$ and carbon in the four samples. As the reaction time increased from 3 to $15 \mathrm{~h}$, the Ni-BTC MOF gradually transformed from a solid structure into a hollow yolk-shell structure. This latter structure is more likely to undergo a complete selenization process, leading to higher $\mathrm{NiSe}_{2}$ contents in the composite products; we also note that $\mathrm{NiSe}_{2}$ has a larger theoretical capacity than $\mathrm{Ni}_{3} \mathrm{Se}_{4}$. We shall conclude that $\mathrm{NiSe}_{x} @ \mathrm{C} / \mathrm{CNTs}-10 \mathrm{~h}$ exhibits the best rate performance and the highest discharge specific capacity among the four samples on account of its optimal balance between internal cavity structure and biphasic composition.

Subsequently, we studied the electrochemical performance of the $\mathrm{NiSe}_{x} @ \mathrm{C} / \mathrm{CNTs}-10 \mathrm{~h}$ sample in greater detail. The
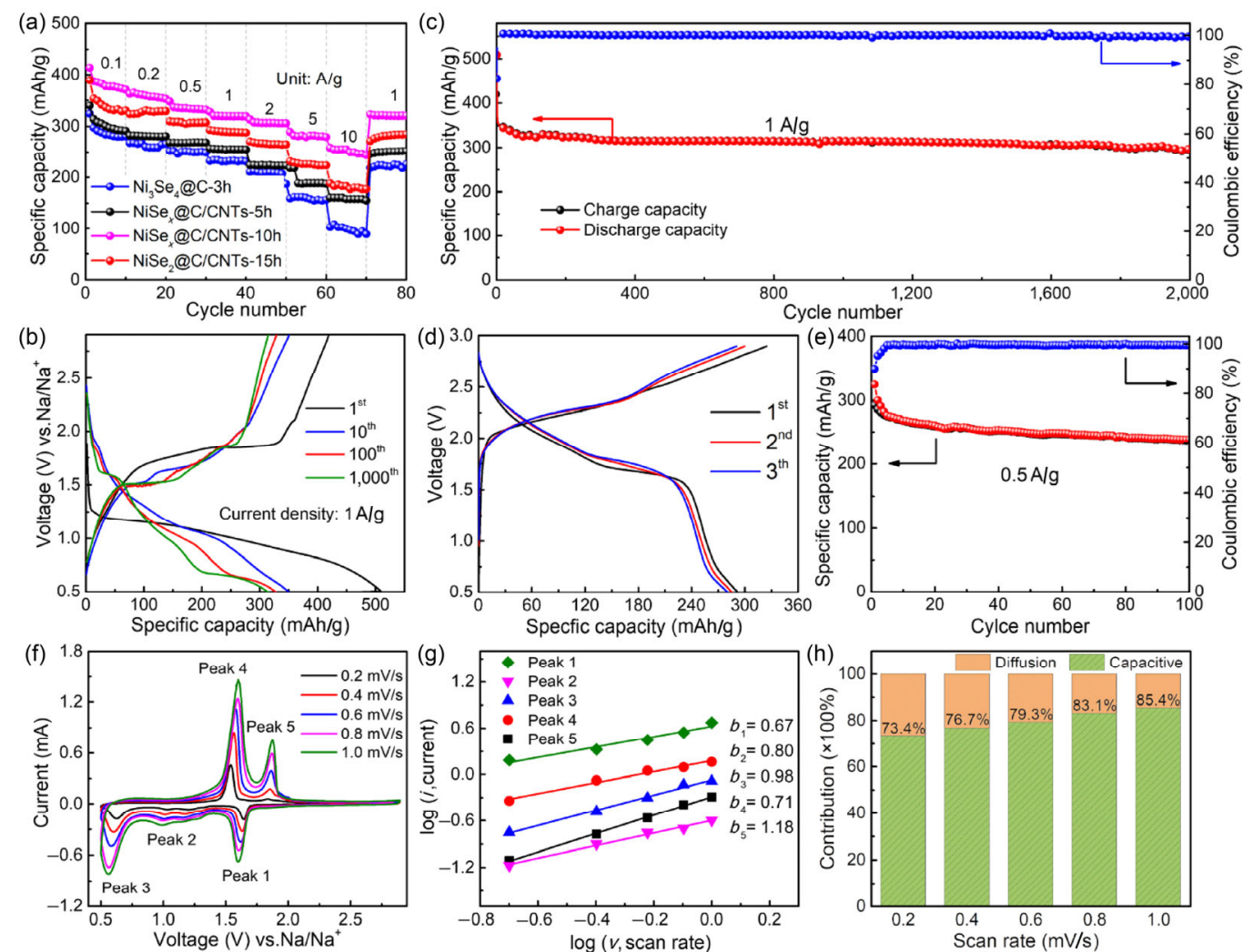

Figure 5 Electrochemical performance of the four nickel selenides nanocomposites in the cut-off voltage range 0.5-2.9 V. (a) Charge-discharge curves of $\mathrm{NiSe}_{x} @ \mathrm{C} / \mathrm{CNTs}-10 \mathrm{~h}$ at different cycle numbers at $1 \mathrm{~A} / \mathrm{g}$. (b) Cycling stability of NiSe $e_{x} @ \mathrm{C} / \mathrm{CNTs}-10$ at $1 \mathrm{~A} / \mathrm{g}$. (c) Rate capability evaluated at various current densities ranging from 0.1 to $10 \mathrm{~A} / \mathrm{g}$. (d) Charge and discharge profiles. (e) Cycling performance and Coulombic efficiency of the NiSe $@$ C/CNTs-10//NVP full cells at $0.5 \mathrm{~A} / \mathrm{g}$. (f) CV profiles of NiSe $@ \mathrm{C} / \mathrm{CNTs}-10 \mathrm{~h}$ at different scan rates. (g) Corresponding $\log i$ versus $\log v$ plot at each redox peak. (h) Pseudocapacitive contribution at a scan rate of $1 \mathrm{mV} / \mathrm{s}$. 
corresponding discharge and charge profiles at a current density of $1 \mathrm{~A} / \mathrm{g}$ are displayed in Fig. 5(b). The initial discharge and charge capacities are 509.3 and $419.4 \mathrm{mAh} / \mathrm{g}$, respectively, yielding an initial coulombic efficiency of $82.3 \%$. The irreversible capacity loss in the first cycle is mainly ascribed to the irreversible decomposition of electrolyte and the formation of a solid-electrolyte interface (SEI) layer [51, 52]. Notably, the initial charge and discharge profiles are rather different from those that followed, which is mostly attributed to the activation of nickel selenide and side reactions that make initial sodiation and desodiation unstable $[50,53]$. The discharge and charge curves however almost overlap after 100 cycles and stable discharge plateaus at $1.60,1.03,0.65 \mathrm{~V}$ and charge plateaus at $1.53,1.86 \mathrm{~V}$ are well maintained. Figure $5(\mathrm{c})$ shows the long-term cycle performance of $\mathrm{NiSe}_{x} @ \mathrm{C} / \mathrm{CNTs}-10 \mathrm{~h}$ at $1 \mathrm{~A} / \mathrm{g}$. Even after 2,000 cycles, the discharge capacity remains at $306.3 \mathrm{mAh} / \mathrm{g}$ with a capacitance decay ratio of only $0.01 \%$ per cycle. In addition, the Coulombic efficiency of $\mathrm{NiSe}_{x} @ \mathrm{C} / \mathrm{CNTs}-10 \mathrm{~h}$ remains above 99.6\% after the fourth discharge/charge cycle, indicating excellent energy conversion efficiency. For comparison, we also investigate the electrochemical performance of $\mathrm{Ni}_{3} \mathrm{Se}_{4} @ \mathrm{C}-3 \mathrm{~h}$, as shown in Fig. S10 in the ESM. Unlike NiSe $@$ C/CNTs-10h, almost no evident plateaus are observed, indicating an incomplete electrochemical reaction process. A lower discharge capacity of $242.8 \mathrm{mAh} / \mathrm{g}$ is achieved after 2,000 cycles. The outstanding electrochemical performance of our $\mathrm{NiSe}_{x} @ \mathrm{C} / \mathrm{CNTs}-10 \mathrm{~h}$ is compared with other nickel selenide anodes in Table S1 in the ESM, demonstrating its advantageous long cyclic stability and high rate performance. Additionally, the practical value of NiSe @C/CNTs-10h was evaluated in full cells with $\mathrm{Na}_{3} \mathrm{~V}_{2}\left(\mathrm{PO}_{4}\right)_{3}$ (NVP) as the cathode. The flower-like NVP delivers a stable reversible capacity of $95.4 \mathrm{mAh} / \mathrm{g}$ at $1 \mathrm{C}$ in a half-cell (Fig. S11 in the ESM). The NVP//NiSe $@$ C/CNTs-10 full cells showed a remarkable discharge capacity of $238.5 \mathrm{mAh} / \mathrm{g}$ at $0.5 \mathrm{~A} / \mathrm{g}$ after 100 cycles with a discharge plateau of $2.0 \mathrm{~V}$ (Figs. 5(d) and 5(e)), demonstrating the potential of $\mathrm{NiSe}_{x} @ \mathrm{C} / \mathrm{CNTs}-10 \mathrm{~h}$ as an anode for high-performance sodium ion batteries.

It has been reported that the high-rate performance of electrode materials is related to its potential pseudocapacitive behavior upon continuous discharge/charge cycling. In order to explore the electrochemical reaction dynamics of $\mathrm{NiSe}_{x} @ \mathrm{C} /$ CNTs-10h, we measured its cyclic voltammettry (CV) curves at various scan rates from 0.2 to $1.0 \mathrm{mV} / \mathrm{s}$ between 0.5 and $2.9 \mathrm{~V}$ (Fig. 5(f)). Generally, the peak current $(i)$ and scan rate $(v)$ obey the following equations [19]

$$
\begin{aligned}
& i=a v^{b} \\
& \log (i)=\log (a)+b \cdot \log (v)
\end{aligned}
$$

where $a$ and $b$ are adjustable parameters, and $b$ is determined from the slope of the $\log (i)$ vs. $\log (v)$ plot. Normally, when $b=$ 0.5 , the electrochemical sodium storage reaction is controlled by ionic diffusion. However, as $b$ approaches 1.0, the sodium storage process is dominated by pseudocapacitance. As shown in Fig. 5(g), the $b$-values (fitted slopes) of the plots from the five peaks in Fig. 5(f) are 0.67, 0.80, 0.98, 0.71 and 1.18. These results show that pseudocapacitive behavior dominates the repeated redox processes, giving rise to rapid $\mathrm{Na}^{+}$intercalation/extraction kinetics. Furthermore, the total pseudocapacitive contribution can be calculated according to the equation: $i=k_{1} v+k_{2} v^{0.5}$ [54], where $k_{1} v$ and $k_{2} v^{0.5}$ represent the pseudocapacitive and ionic diffusion contributions, respectively. As presented in Fig. 5(h), the total pseudocapacitive contribution of the $\mathrm{NiSe}_{x} @ \mathrm{C} /$ CNTs-10 increased from $73.4 \%$ to $85.4 \%$ as the scan rates increased from 0.2 to $1.0 \mathrm{mV} / \mathrm{s}$. This result is similar to that of other metal sulfides/selenides $[18,55]$. Our results demonstrate that pseudocapacitive behavior provides a major capacitance contribution, especially at high scan rates, on account of the unique CNT-bridged yolk-shell structure effectively reducing the diffusion path. For comparison, the pseudocapacitive behavior of $\mathrm{Ni}_{3} \mathrm{Se}_{4} @ \mathrm{C}-3 \mathrm{~h}$ was also evaluated, as shown in Fig. S12 in the ESM. Again, five distinct current peaks are detected at the same voltages, though the peak intensities are relatively smaller. The $b$-values of the five peaks are close to those of the $\mathrm{NiSe}_{x} @ \mathrm{C} /$ CNTs-10h sample, indicating partial pseudocapacitive behavior during the electrochemical process. However, as shown in Figs. S12(c) and S12(d) in the ESM, the pseudocapacitive contributions of $\mathrm{Ni}_{3} \mathrm{Se}_{4} @ \mathrm{C}-3 \mathrm{~h}$ are lower than those of $\mathrm{NiSe}_{x} @ \mathrm{C} /$ CNTs-10h, mainly due to the sluggish electrochemical reaction between $\mathrm{Na}^{+}$ions and $\mathrm{Ni}_{3} \mathrm{Se}_{4} @ \mathrm{C}-3$ h. Furthermore, the effects of the voltage window and the electrolyte have been also systematically studied (Figs. S13-S15 in the ESM)

To further understand the possible sodiation/desodiation mechanisms of $\mathrm{NiSe}_{x} @ \mathrm{C} / \mathrm{CNTs}-10 \mathrm{~h}$, ex-situ XRD, SAED, HRTEM, electrochemical impedance spectroscopy (EIS) and SEM measurements were performed at different stages of the electrochemical reaction (Figs. 6(a)-6(e), Figs. S16 and S17 in the ESM). Figure 6(a) presents the ex-situ XRD patterns of the $\mathrm{NiSe}_{x} @ \mathrm{C} / \mathrm{CNTs}-10 \mathrm{~h}$ electrodes at several charge/discharge stage. As the discharge voltage decreases from the initial potential value of 1.9 to $0.5 \mathrm{~V}$, the typical diffraction peaks of cubic $\mathrm{NiSe}_{2}$ and monoclinic $\mathrm{Ni}_{3} \mathrm{Se}_{4}$ diminish gradually before vanishing completely. At the same time, the weak diffraction peaks that emerge at $37.2^{\circ}, 44.0^{\circ}$ and $44.5^{\circ}$ can be assigned to the (220) and (311) planes of $\mathrm{Na}_{2} \mathrm{Se}$ (JCPDS No.47-1699) and the (111) plane of metallic Ni (JCPDS No.04-0850), respectively [49]. During the subsequent charging process from 0.5 to $2.9 \mathrm{~V}$, the strong characteristic diffraction peaks of $\mathrm{NiSe}_{2}$ and $\mathrm{Ni}_{3} \mathrm{Se}_{4}$ gradually recover, while those of $\mathrm{Ni}$ and $\mathrm{Na}_{2} \mathrm{Se}$ gradually disappear. The presence of these intermediates was further verified by $e x$-situ SAED patterns and HRTEM images. The ex-situ SADE (Fig. 6(b)) clearly discloses the polycrystalline diffraction rings of the (220) and (400) planes of $\mathrm{Na}_{2} \mathrm{Se}$, the (111) plane of $\mathrm{Ni}$, and (003) plane of graphite when discharged to $0.5 \mathrm{~V}$. The lattice fringes of these discharge intermediates are also shown in Fig. 6(c). After the cell was recharged to $2.6 \mathrm{~V}$ once more, the ex-situ SAED (Fig. 6(d)) and ex-situ HRTEM (Fig. 6(e)) reveal the typical diffraction rings and lattice planes of $\mathrm{NiSe}_{2}$ and $\mathrm{Ni}_{3} \mathrm{Se}_{4}$, respectively, indicating a completely reversible reaction process. Based on the above results and the reported literature $[50,56]$, the possible reaction mechanism for the electrochemical behavior of $\mathrm{NiSe}_{x} @ \mathrm{C} / \mathrm{CNTs}-10 \mathrm{~h}$ can be summarized as follows

Discharge process:

$$
\begin{aligned}
& \mathrm{NiSe}_{2}+x \mathrm{Na}^{+}+x \mathrm{e}^{-} \rightarrow \mathrm{Na}_{x} \mathrm{NiSe}_{2} \\
& \mathrm{Ni}_{3} \mathrm{Se}_{4}+2 x \mathrm{Na}^{+}+2 x \mathrm{e}^{-} \rightarrow 2 \mathrm{Na}_{x} \mathrm{NiSe}_{2}+\mathrm{Ni} \\
& \mathrm{Na}_{x} \mathrm{NiSe}_{2}+(2-x) \mathrm{Na}^{+}+(2-x) \mathrm{e}^{-} \rightarrow \mathrm{NiSe}+\mathrm{Na}_{2} \mathrm{Se} \\
& \mathrm{NiSe}+2 \mathrm{Na}^{+}+2 \mathrm{e}^{-} \rightarrow \mathrm{Ni}+\mathrm{Na}_{2} \mathrm{Se} \\
& \text { Charge process: } \\
& \mathrm{Ni}+2 \mathrm{Na}_{2} \mathrm{Se} \rightarrow \mathrm{Na}_{x} \mathrm{NiSe}_{2}+(4-x) \mathrm{Na}^{+}+(4-x) \mathrm{e}^{-} \\
& 2 \mathrm{Na}_{x} \mathrm{NiSe}_{2}+\mathrm{Ni} \rightarrow \mathrm{Ni}_{3} \mathrm{Se}_{4}+2 x \mathrm{Na}^{+}+2 x \mathrm{e}^{-} \\
& \mathrm{Na}_{x} \mathrm{NiSe}_{2} \rightarrow \mathrm{NiSe}_{2}+x \mathrm{Na}^{+}+x \mathrm{e}^{-}
\end{aligned}
$$

Calculations based on density functional theory (calculation method was shown in the ESM) were performed to further study the $\mathrm{Na}$ insertion at the interface between $\mathrm{Ni}_{3} \mathrm{Se}_{4}$ and $\mathrm{NiSe}_{2}$. In Fig. 6(f), the insertion energies of $\mathrm{Na}$ interstitials into pure $\mathrm{Ni}_{3} \mathrm{Se}_{4}$, pure $\mathrm{NiSe}_{2}$, and at their interface have been compared. The large positive insertion energy leads to a low concentration of $\mathrm{Na}$ diffused into bulk $\mathrm{NiSe}_{2}$ and $\mathrm{Ni}_{3} \mathrm{Se}_{4}$. 
(a)

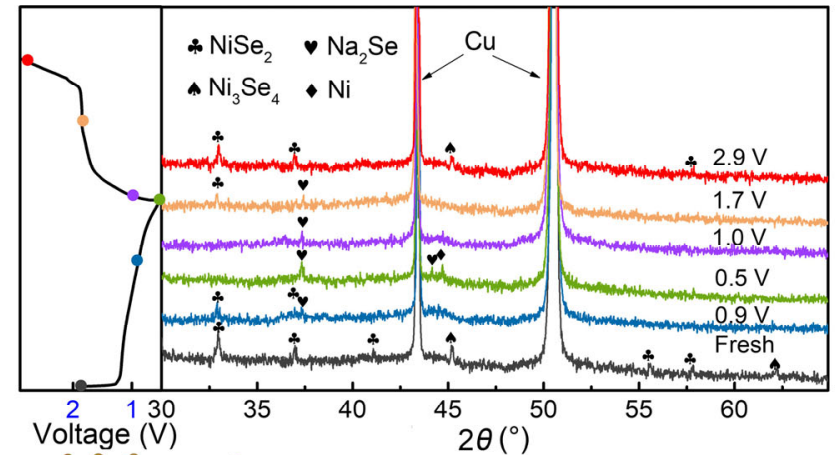

(f)

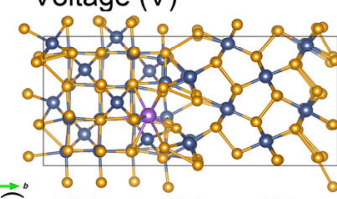

(g)

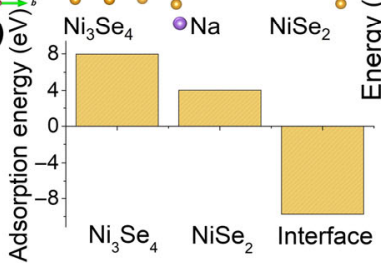

(h)

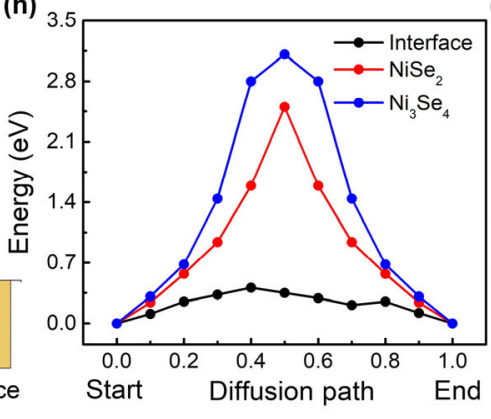

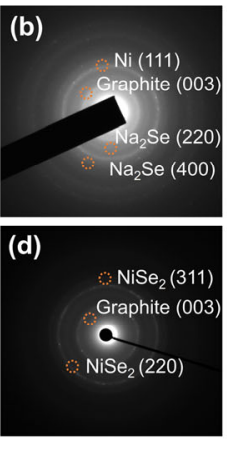

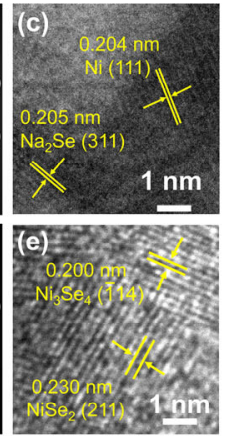

(i)

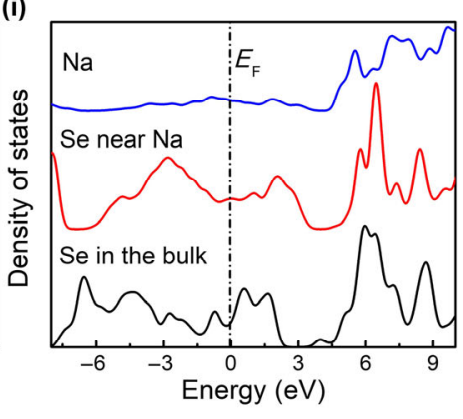

Figure 6 Reaction mechanism: (a) ex-situ XRD analysis of the NiSe $x_{x} @ \mathrm{C} / \mathrm{CNTs}-10 \mathrm{~h}$ electrodes at different charge/discharge states and ex-situ SAED, HRTEM of NiSe $@$ C/CNTs-10h at different cycling stages: ((b), (c)) discharge to $0.5 \mathrm{~V},((\mathrm{~d}),(\mathrm{e}))$ charge to $2.6 \mathrm{~V}$, (f) scheme of $\mathrm{Na}^{+}$transfer in phase boundary, (g) calculation of the $\mathrm{Na}^{+}$adsorption energy of $\mathrm{Ni}_{3} \mathrm{Se}_{4}, \mathrm{NiSe}_{2}$ and the interface, (h) the energy minimum diffusion pathway of a Na atom along the interface, (i) calculated density of states (DOS) of Na, Se near Na, and Se at the interface as shown in (f).

However, the large negative insertion energy of $\mathrm{Na}$ at the interface suggests that $\mathrm{Na}$ tends to spontaneously diffuse into the interfacial area between the two selenides. We also estimated the diffusion barrier of $\mathrm{Na}$ at the interface to be around $0.41 \mathrm{eV}$, whereas the diffusion barrier in pure $\mathrm{NiSe}_{2}$ and $\mathrm{Ni}_{3} \mathrm{Se}_{4}$ is larger than $3.0 \mathrm{eV}$, as shown in Fig. $6(\mathrm{~g})$. This confirms that diffusion along interfaces or grain boundaries is preferable. In Fig. 6(h), the atomic structure of $\mathrm{Na}$ at the interface is shown, as well as the diffusion path of $\mathrm{Na}$ along the interface. The lattice mismatch at the interface creates a large strain field which helps to accommodate the extra $\mathrm{Na}$ atom. The insertion of $\mathrm{Na}$ significantly affects the local atomic structure. Hirshfield analysis confirms that there is charge transfer of $0.12 \mathrm{eV}$ between $\mathrm{Na}$ and neighboring $\mathrm{Se}$ atoms. Therefore, $\mathrm{Na}$ has a strong interaction with the interface region in $\mathrm{Ni}_{3} \mathrm{Se}_{4}$ and $\mathrm{NiSe}_{2}$. The DOS around the Fermi level of Se at the interface near $\mathrm{Na}$ atoms has been completely changed compared with the bulk ones, indicating a strong interaction of the $\mathrm{Na}$ with the interfacial atoms. This atomic and electronic interaction could lead to higher insertion concentrations and large charge transfer, both of which facilitate sodium storage at the interface region.

\section{Conclusions}

Four types of Ni-BTC MOFs with contrasting morphologies were fabricated via a facile solvothermal reaction using different reaction times. The results show that the morphologies of the Ni-BTC precursors gradually changed from solid spheres to hollow urchins as the solvothermal time increased from 3 to $15 \mathrm{~h}$. After subsequent pyrolysis followed by selenization, four carbon-coated or CNT-bridged metal selenide composites were obtained. These showed a gradual evolution from $\mathrm{Ni}_{3} \mathrm{Se}_{4}$ to $\mathrm{NiSe}_{2}$ as a function of the original MOF synthesis time. When used as anodes in SIBs, NiSe $e_{x} @ \mathrm{C} / \mathrm{CNTs}-10 \mathrm{~h}$ exhibited a high specific capacity, long cycle stability, and high rate performance. The interface between $\mathrm{Ni}_{3} \mathrm{Se}_{4}$ and $\mathrm{NiSe}_{2}$ lowers the $\mathrm{Na}^{+}$insertion energy, facilitating the reaction kinetics during electrochemical cycling. CNT-bridged yolk-shell composites have unique nanostructures that combine the porous features from the MOFderived materials with the advantages of CNTs. The hollow porous structure provides protection against volume changes, whilst the CNTs introduce a large number of mesopores, shortening charge transfer paths and improving the utilization efficiency of the active materials. The above results demonstrate that the use of MOF-derived carbons combined with selenization provides an effective route for synthesizing metal selenide nanocomposites and offers a novel strategy for obtaining highperformance electrode materials.

\section{Experimental methods}

\subsection{Synthesis of graphitic carbon-coated $\mathrm{Ni}_{3} \mathrm{Se}_{4}$ nano- sphere hybrids $\left(\mathrm{Ni}_{3} \mathrm{Se}_{4} @ \mathrm{C}\right)$ and CNT-bridged carbon- coated $\mathrm{NiSe}_{2}$ nanospheres (NiSe $@$ C/CNTs)}

All chemical reagents are analytically pure and purchased from Aladdin Chemical Co. Ltd, China. The Ni-BTC was synthesized by a typical hydrothermal method. First, ethanol, $\mathrm{N}, \mathrm{N}$-dimethylformamide (DMF) and deionized water with a volume ratio of 1:1:1 were mixed to form $30 \mathrm{~mL}$ mixed solution. Then, $432 \mathrm{mg}$ of $\mathrm{Ni}\left(\mathrm{NO}_{3}\right)_{2} \cdot 6 \mathrm{H}_{2} \mathrm{O}, 150 \mathrm{mg}$ of 1,3,5-benzenetricarboxylic acid $\left(\mathrm{H}_{3} \mathrm{BTC}\right)$ and $1.5 \mathrm{~g}$ of polyvinylpyrrolidone (PVP, K-36) were dissolved in the prepared mixture with continuous stirring for $30 \mathrm{~min}$. The obtained solution was transferred into a $50 \mathrm{~mL}$ Teflon-lined autoclave and heated to $150{ }^{\circ} \mathrm{C}$ respectively for $3,5,10,15 \mathrm{~h}$ to obtain four products with different morphology. The green products were collected by centrifugation and washed by deionized water and ethanol several times, then dried in an oven at $60{ }^{\circ} \mathrm{C}$ overnight. Next, the four precursors were annealed under a mixed $\mathrm{H}_{2} / \mathrm{Ar}$ flow with $5 \mathrm{vol} \% \mathrm{H}_{2}$ at $435{ }^{\circ} \mathrm{C}$ for $8 \mathrm{~h}$ with a heating rate of $2{ }^{\circ} \mathrm{C} / \mathrm{min}$ to obtain four Nickel-carbon composites. Finally, the selenization process was accomplished by placing the 
nickel-carbon composites and excessive selenium powder separately on both sides of the porcelain and annealed under the $\mathrm{H}_{2} / \mathrm{Ar}$ flow at $400{ }^{\circ} \mathrm{C}$ for $3 \mathrm{~h}$.

\subsection{Material characterization}

The morphology of as-prepared composites was characterized by FESEM (JEOL JSM-6700F) and TEM (JEOL; JEM-2100F). EDX measurements were performed on an FEI Quanta 250 FEG SEM. X-ray diffraction (XRD; Bruker AXS D8 Advance) to acquire the crystallographic information. The total carbon content was obtained by thermogravimetric analysis (PerkinElmer TGA 7) carried out under an air flow of $200 \mathrm{~mL} / \mathrm{min}$ with a heating rate of $10{ }^{\circ} \mathrm{C} / \mathrm{min}$. The chemical compositions of samples were investigated by XPS measurements, performed on ESCALab 250 (USA) with monochromatic Al K sources. To obtain the specific surface area and pore size distribution of composites, $\mathrm{N}_{2}$ sorption measurements and the BET method (ASAP 2020 PLUS HD88) were employed. Raman spectra were collected by a laser Raman spectrometer (Horiba JOBIN YVON; HR 800).

\subsection{Electrochemical measurements}

The electrochemical tests were carried out using CR2025 coin-type cells, which were assembled in an argon-filled glovebox (Dellix, $\left[\mathrm{O}_{2}\right]<1 \mathrm{ppm},\left[\mathrm{H}_{2} \mathrm{O}\right]<1 \mathrm{ppm}$ ). The working electrodes were prepared by mixing the active material, carbon black (Super-P-Li) and binder (sodium carboxymethylcellulose, $\mathrm{NaCMC}$ ) at a mass ratio of 7:2:1 using deionized water as solvent. After $24 \mathrm{~h}$ magnetic stirring at room temperature, the mixing slurry was pasted uniformly onto copper foil $(D=$ $12.6 \mathrm{~mm}$ ), then dried in a vacuum oven at $40^{\circ} \mathrm{C}$ overnight. The mass loading of active materials in the anodes is about $1.5 \mathrm{mg} / \mathrm{cm}$. Glass microfibers (Whatman), a circular $\mathrm{Na}$ tablets and $1 \mathrm{M} \mathrm{NaCF}_{3} \mathrm{SO}_{3}$ in DEGDME were employed as the separator, counter electrode and electrolyte, respectively. For comparison, the carbonate-based electrolytes including $1.0 \mathrm{M}$ $\mathrm{NaClO}_{4}$ in propylene carbonate (PC) with $5 \mathrm{wt}$.\% fluoroethylene carbonate (FEC) and $1.0 \mathrm{M} \mathrm{NaPF}_{6}$ in ethylene carbonate/ dimethyle carbonate $(\mathrm{EC} / \mathrm{DEC} ; \mathrm{v} / \mathrm{v}=1: 1)$ were also used to investigate the cycle stability of as-prepared $\mathrm{NiSe}_{x} @ \mathrm{C} /$ CNTs-10h through assembling coin-type half-cells. CV and EIS were conducted on a CHI660D electrochemical workstation. Galvanostatic discharge/charge cycles were performed on a NEWARE battery tester within a voltage window of $0.5-2.9 \mathrm{~V}$ in a thermotank at $24^{\circ} \mathrm{C}$. The specific capacity was calculated based on the total weight of as-prepared composites in the electrode. To further estimate the electrochemical performance of as-prepared $\mathrm{NiSe}_{x} @ \mathrm{C} / \mathrm{CNTs}$-10h, flower-like NVP was used as cathodic materials to assemble NVP//NiSe $e_{0} @ \mathrm{C} / \mathrm{CNTs}-10 \mathrm{~h}$ full cells. Before the preparation of full cells, NiSe $@$ C/CNTs-10h anodes were electrochemically activated for three cycles. Then NVP cathodes and activated NiSe $e_{x}$ C/CNTs-10h anodes were paired in a weight ratio of $8: 1$ with $1.0 \mathrm{M} \mathrm{NaCF}_{3} \mathrm{SO}_{3}$ in DEGDME as electrolyte.

\subsection{Calculation method}

The first-principle calculation has been done with CASTEP planewave pseuopotential package [54]. An ultrasoft pseudopotential has been used with a cut-off energy of $450 \mathrm{eV}$. The supercell used are large than 15 Ang so only Gamma point was used for reciprocal space integration. Hubbard $U$ term has been added on $\mathrm{Ni}$ with a $\mathrm{U}$ value of $4.5 \mathrm{eV}$ to describe the localized semi-core $\mathrm{d}$ states [55]. The BFGS algorithm has been used to relax the structure with a residual force of less than $0.02 \mathrm{eV} / \AA$ [56].

\section{Acknowledgements}

This research was supported by the National Natural Science Foundation of China (No. 51773165), Project of National Defense Science and Technology Innovation Special Zone (No. JZ-20171102), Shaanxi Post-doctoral Foundation (No. 2016BSHYDZZ20), Key Laboratory Construction Program of Xian Municipal Bureau of Science and Technology (No. 201805056ZD7CG40), Innovation Capability Support Program of Shaanxi (No. 2018PT-28 and 2019PT-05). The numerical calculations in this paper have been done on the supercomputing system in the Supercomputing Center of Wuhan University. A. K. C. thanks the Ras al Khaimah Centre for Advanced Materials for financial support. J. H. thanks the financial support (No. DE190100803). The authors would like to thank the Center for Advancing Materials Performance from the Nanoscale (CAMP-Nano) for allowing the use of field-emission scanning electron microscopy. We also thank Miss Jiao Li at Instrument Analysis Center of Xian Jiaotong University for their assistance with TEM mapping analysis.

Electronic Supplementary Material: Supplementary material (additional FESEM, TEM images, EDX, XRD patterns, crystal structures, XPS spectra, BET, EIS analysis, electrochemical characterizations and comparison tables) is available in the online version of this article at https://doi.org/10.1007/s12274-0202848-z.

Open Access This article is licensed under a Creative Commons Attribution 4.0 International License, which permits use, sharing, adaptation, distribution and reproduction in any medium or format, as long as you give appropriate credit to the original author(s) and the source, provide a link to the Creative Commons licence, and indicate if changes were made.

The images or other third party material in this article are included in the article's Creative Commons licence, unless indicated otherwise in a credit line to the material. If material is not included in the article's Creative Commons licence and your intended use is not permitted by statutory regulation or exceeds the permitted use, you will need to obtain permission directly from the copyright holder.

To view a copy of this licence, visit http://creativecommons.org/licenses/by/4.0/.

\section{References}

[1] Hwang, J. Y.; Myung, S. T.; Sun, Y. K. Sodium-ion batteries: Present and future. Chem. Soc. Rev. 2017, 46, 3529-3614.

[2] Kim, H.; Kim, H.; Ding, Z.; Lee, M. H.; Lim, K.; Yoon, G.; Kang, K. Recent progress in electrode materials for sodium-ion batteries. $A d v$. Energy Mater. 2016, 6, 1600943.

[3] Xie, F. X.; Zhang, L.; Ye, C.; Jaroniec, M.; Qiao, S. Z. The application of hollow structured anodes for sodium-ion batteries: From simple to complex systems. Adv. Mater. 2019, 31, 1800492.

[4] Liu, Y. Y.; Zhou, G. M.; Liu, K.; Cui, Y. Design of complex nanomaterials for energy storage: Past success and future opportunity. Acc. Chem. Res. 2017, 50, 2895-2905.

[5] Deng, J. Q.; Luo, W. B.; Chou, S. L.; Liu, H. K.; Dou, S. X. Sodium-ion batteries: From academic research to practical commercialization. Adv. Energy Mater. 2018, 8, 1701428.

[6] Chen, S. Q.; Wu, C.; Shen, L. F.; Zhu, C. B.; Huang, Y. Y.; Xi, K.; Maier, J.; Yu, Y. Challenges and perspectives for NASICON-type electrode materials for advanced sodium-ion batteries. Adv. Mater. 2017, 29, 1700431.

[7] Deng, J.; Gong, Q. F.; Ye, H. L.; Feng, K.; Zhou, J. H.; Zha, C. Y.; Wu, J. H.; Chen, J. M.; Zhong, J.; Li, Y. G. Rational synthesis and assembly of $\mathrm{Ni}_{3} \mathrm{~S}_{4}$ nanorods for enhanced electrochemical sodium-ion 
storage. ACS Nano 2018, 12, 1829-1836.

[8] Zhou, L. M.; Zhang, K.; Sheng, J. Z.; An, Q. Y.; Tao, Z. L.; Kang, Y. M.; Chen, J.; Mai, L. Q. Structural and chemical synergistic effect of $\mathrm{CoS}$ nanoparticles and porous carbon nanorods for high-performance sodium storage. Nano Energy 2017, 35, 281-289.

[9] Liu, D. H.; Li, W. H.; Zheng, Y. P.; Cui, Z.; Yan, X.; Liu, D. S.; Wang, J. W.; Zhang, Y.; Lü, H. Y.; Bai, F. Y. et al. In situ encapsulating $\alpha$-MnS into N,S-codoped nanotube-like carbon as advanced anode material: $\alpha \rightarrow \beta$ phase transition promoted cycling stability and superior $\mathrm{Li} / \mathrm{Na}$-storage performance in half/full cells. Adv. Mater. 2018, 30, 1706317.

[10] Chao, D. L.; Ouyang, B.; Liang, P.; Huong, T. T. T.; Jia, G. C.; Huang, H.; Xia, X. H.; Rawat, R. S.; Fan, H. J. C-plasma of hierarchical graphene survives $\mathrm{SnS}$ bundles for ultrastable and high volumetric Na-Ion storage. Adv. Mater. 2018, 30, 1804833.

[11] Wang, Q. H.; Zhang, W. C.; Guo, C.; Liu, Y. J.; Wang, C.; Guo, Z. P. In Situ construction of 3D interconnected $\mathrm{FeS} @ \mathrm{Fe}_{3} \mathrm{C} @$ Graphitic carbon networks for high-performance sodium-ion batteries. Adv. Funct. Mater. 2017, 27, 1703390.

[12] Su, D. W.; Kretschmer, K.; Wang, G. X. Improved electrochemical performance of Na-Ion batteries in ether-based electrolytes: A case study of ZnS nanospheres. Adv. Energy Mater. 2016, 6, 1501785

[13] Dong, S. H.; Li, C. X.; Ge, X. L.; Li, Z. Q.; Miao, X. G.; Yin, L. W.

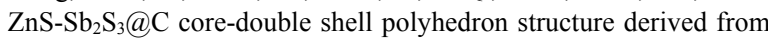
metal-organic framework as anodes for high performance sodium ion batteries. ACS Nano 2017, 11, 6474-6482.

[14] Hou, H. S.; Banks, C. E.; Jing, M. J.; Zhang, Y.; Ji, X. B. Carbon quantum dots and their derivative $3 \mathrm{D}$ porous carbon frameworks for sodium-ion batteries with ultralong cycle life. Adv. Mater. 2015, 27, 7861-7866.

[15] Hu, Z.; Liu, Q. N.; Chou, S. L.; Dou, S. X. Advances and challenges in metal sulfides/selenides for next-generation rechargeable sodium-ion batteries. Adv. Mater. 2017, 29, 1700606.

[16] Xi, K.; He, D. Q.; Harris, C.; Wang, Y. K.; Lai, C.; Li, H. L.; Coxon, P. R.; Ding, S. J.; Wang, C.; Kumar, R. V. Enhanced sulfur transformation by multifunctional $\mathrm{FeS}_{2} / \mathrm{FeS} / \mathrm{S}$ composites for highvolumetric capacity cathodes in lithium-sulfur batteries. $\mathrm{Adv}$. Sci. 2019, 6, 1800815 .

[17] Xi, K.; Chen, B. A.; Li, H. L.; Xie, R. S.; Gao, C. L.; Zhang, C.; Kumar, R. V.; Robertson, J. Soluble polysulphide sorption using carbon nanotube forest for enhancing cycle performance in a lithiumsulphur battery. Nano Energy 2015, 12, 538-546.

[18] Hu, X.; Jia, J. C.; Wang, G. X.; Chen, J. X.; Zhan, H. B.; Wen, Z. H. Reliable and general route to inverse opal structured nanohybrids of carbon-confined transition metal sulfides quantum dots for highperformance sodium storage. Adv. Energy Mater. 2018, 8, 1801452.

[19] Ge, P.; Hou, H. S.; Li, S. J.; Yang, L.; Ji, X. B. Tailoring rod-like $\mathrm{FeSe}_{2}$ coated with nitrogen-doped carbon for high-performance sodium storage. Adv. Funct. Mater. 2018, 28, 1801765.

[20] Lu, S. Y.; Zhu, T. X.; Wu, H.; Wang, Y. K.; Li, J.; Abdelkader, A.; Xi, K.; Wang, W.; Li, Y. G.; Ding, S. J. et al. Construction of ultrafine ZnSe nanoparticles on/in amorphous carbon hollow nanospheres with high-power-density sodium storage. Nano Energy 2019, 59, $762-772$.

[21] Wei, X. J.; Tang, C. J.; An, Q. Y.; Yan, M. Y.; Wang, X. P.; Hu, P.; Cai, X. Y.; Mai, L. Q. FeSe 2 clusters with excellent cyclability and rate capability for sodium-ion batteries. Nano Res. 2017, 10, 32023211.

[22] Liu, H.; Guo, H.; Liu, B. H.; Liang, M. F.; Lv, Z. L.; Adair, K. R.; Sun, X. L. Few-layer $\mathrm{MoSe}_{2}$ nanosheets with expanded (002) planes confined in hollow carbon nanospheres for ultrahigh-performance Na-Ion batteries. Adv. Funct. Mater. 2018, 28, 1707480.

[23] Niu, F. E.; Yang, J.; Wang, N. N.; Zhang, D. P.; Fan, W. L.; Yang, J.; Qian, Y. T. MoSe $e_{2}$-covered N,P-doped carbon nanosheets as a longlife and high-rate anode material for sodium-ion batteries. Adv. Funct. Mater. 2017, 27, 1700522.

[24] Tang, C. J.; Wei, X. J.; Cai, X. Y.; An, Q. Y.; Hu, P.; Sheng, J. Z.; Zhu, J. X.; Chou, S. L.; Wu, L. M.; Mai, L. Q. ZnSe microsphere/ multiwalled carbon nanotube composites as high-rate and long-life anodes for sodium-ion batteries. ACS Appl. Mater. Interfaces 2018, 10, 19626-19632.

[25] Yi, Y. Y.; Sun, Z. T.; Li, C.; Tian, Z. N.; Lu, C.; Shao, Y. L.; Li, J.;
Sun, J. Y.; Liu, Z. F. Designing 3D biomorphic nitrogen-doped $\mathrm{MoSe}_{2}$ /graphene composites toward high-performance potassium-ion capacitors. Adv. Funct. Mater. 2020, 30, 1903878.

[26] Xia, Z.; Sun, H.; He, X.; Sun, Z. T.; Lu, C.; Li, J.; Peng, Y.; Dou, S. X.; Sun, J. Y.; Liu, Z. F. In situ construction of $\mathrm{CoSe}_{2} @$ verticaloriented graphene arrays as self-supporting electrodes for sodium-ion capacitors and electrocatalytic oxygen evolution. Nano Energy 2019, $60,385-393$

[27] Lu, C.; Li, Z. Z.; Xia, Z.; Ci, H. N.; Cai, J. S.; Song, Y. Z.; Yu, L. H.; Yin, W. J.; Dou, S. X.; Sun, J. Y. et al. Confining MOF-derived SnSe nanoplatelets in nitrogen-doped graphene cages via direct CVD for durable sodium ion storage. Nano Res. 2019, 12, 3051-3058.

[28] Li, Y.; Xu, Y. H.; Wang, Z. H.; Bai, Y.; Zhang, K.; Dong, R. Q.; Gao, Y. N.; Ni, Q.; Wu, F.; Liu, Y. J. et al. Stable carbon-selenium bonds for enhanced performance in Tremella-like 2D chalcogenide battery anode. Adv. Energy Mater. 2018, 8, 1800927.

[29] Zhang, Y. F.; Pan, A. Q.; Ding, L.; Zhou, Z. L.; Wang, Y. P.; Niu, S. Y.; Liang, S. Q.; Cao, G. Z. Nitrogen-doped yolk-shell-structured $\mathrm{CoSe} / \mathrm{C}$ dodecahedra for high-performance sodium ion batteries. ACS Appl. Mater. Interfaces 2017, 9, 3624-3633.

[30] Wu, C.; Jiang, Y.; Kopold, P.; van Aken, P. A.; Maier, J.; Yu, Y. Peapod-like carbon-encapsulated cobalt chalcogenide nanowires as cycle-stable and high-rate materials for sodium-ion anodes. Adv. Mater. 2016, 28, 7276-7283.

[31] Chen, Y. Y.; Ji, S. F.; Zhao, S.; Chen, W. X.; Dong, J. C.; Cheong, W. C.; Shen, R. A.; Wen, X. D.; Zheng, L. R.; Rykov, A. I. et al. Enhanced oxygen reduction with single-atomic-site iron catalysts for a zinc-air battery and hydrogen-air fuel cell. Nat. Commun. 2018, 9, 5422 .

[32] Jagadeesh, R. V.; Murugesan, K.; Alshammari, A. S.; Neumann, H.; Pohl, M. M.; Radnik, J.; Beller, M. MOF-derived cobalt nanoparticles catalyze a general synthesis of amines. Science 2017, 358, 326-332.

[33] Sun, L. M.; Li, R.; Zhan, W. W.; Yuan, Y. S.; Wang, X. J.; Han, X. G.; Zhao, Y. L. Double-shelled hollow rods assembled from nitrogen/sulfur-codoped carbon coated indium oxide nanoparticles as excellent photocatalysts. Nat. Commun. 2019, 10, 2270.

[34] Du, M.; Song, D.; Huang, A. M.; Chen, R. X.; Jin, D. Q.; Rui, K.; Zhang, C.; Zhu, J. X.; Huang, W. Stereoselectively assembled MetalOrganic Framework (MOF) host for catalytic synthesis of carbon hybrids for alkaline-metal-ion batteries. Angew. Chem., Int. Ed. 2019, 58, 5307-5311.

[35] Wang, S. Z.; McGuirk, C. M.; d'Aquino, A.; Mason, J. A.; Mirkin, C. A. Metal-organic framework nanoparticles. Adv. Mater. 2018, 30, 1800202.

[36] Guan, B. Y.; Yu, X. Y.; Wu, H. B.; Lou, X. W. Complex nanostructures from materials based on metal-organic frameworks for electrochemical energy storage and conversion. Adv. Mater. 2017, 29, 1703614.

[37] Kaneti, Y. V.; Tang, J.; Salunkhe, R. R.; Jiang, X. C.; Yu, A. B.; Wu, K. C. W.; Yamauchi, Y. Nanoarchitectured design of porous materials and nanocomposites from metal-organic frameworks. $A d v$. Mater. 2017, 29, 1604898.

[38] Park, S. K.; Kim, J. K.; Chan Kang, Y. Metal-organic frameworkderived $\mathrm{CoSe}_{2} /(\mathrm{NiCo}) \mathrm{Se}_{2}$ box-in-box hollow nanocubes with enhanced electrochemical properties for sodium-ion storage and hydrogen evolution. J. Mater. Chem. A 2017, 5, 18823-18830.

[39] Xi, K.; Cao, S.; Peng, X. Y.; Ducati, C.; Kumar, R. V.; Cheetham, A. K. Carbon with hierarchical pores from carbonized metal-organic frameworks for lithium sulphur batteries. Chem. Commun. 2013, 49, 2192-2194.

[40] Chen, R. J.; Zhao, T.; Tian, T.; Cao, S.; Coxon, P. R.; Xi, K.; FairenJimenez, D.; Kumar, R. V.; Cheetham, A. K. Graphene-wrapped sulfur/metal organic framework-derived microporous carbon composite for lithium sulfur batteries. APL Mater. 2014, 2, 124109.

[41] Tang, Y. C.; Zhao, Z. B.; Hao, X. J.; Wang, Y. W.; Liu, Y.; Hou, Y. N.; Yang, Q.; Wang, X. Z; Qiu, J. S. Engineering hollow polyhedrons structured from carbon-coated $\mathrm{CoSe}_{2}$ nanospheres bridged by CNTs with boosted sodium storage performance. J. Mater. Chem. A 2017, 5, 13591-13600

[42] Zhang, J.; Wan, J. W.; Wang, J. Y.; Ren, H.; Yu, R. B.; Gu, L.; Liu, Y. L.; Feng, S. H.; Wang, D. Hollow multi-shelled structure with metal-organic-framework-derived coatings for enhanced lithium 
storage. Angew. Chem., Int. Ed. 2019, 58, 5266-5271.

[43] Xu, X. J.; Liu, J.; Liu, J. W.; Ouyang, L. Z.; Hu, R. Z.; Wang, H.; Yang, L. C.; Zhu, M. A general Metal-Organic Framework (MOF)derived selenidation strategy for in situ carbon-encapsulated metal selenides as high-rate anodes for Na-Ion batteries. Adv. Funct. Mater. 2018, 28, 1707573.

[44] Zou, F.; Chen, Y. M.; Liu, K. W.; Yu, Z. T.; Liang, W. F.; Bhaway, S. M.; Gao, M.; Zhu, Y. Metal organic frameworks derived hierarchical hollow $\mathrm{NiO} / \mathrm{Ni} / \mathrm{Graphene}$ composites for lithium and sodium storage. ACS Nano 2016, 10, 377-386.

[45] Guan, B. Y.; Yu, L.; Lou, X. W. A dual-metal-organic-framework derived electrocatalyst for oxygen reduction. Energy Environ. Sci. 2016, 9, 3092-3096.

[46] Meng, J. S.; Niu, C. J.; Xu, L. H.; Li, J. T.; Liu, X.; Wang, X. P.; Wu, Y. Z.; Xu, X. M.; Chen, W. Y.; Li, Q. et al. General oriented formation of carbon nanotubes from metal-organic frameworks. J. Am. Chem. Soc. 2017, 139, 8212-8221.

[47] Park, S. K.; Kim, J. K.; Kang, Y. C. Excellent sodium-ion storage performances of $\mathrm{CoSe}_{2}$ nanoparticles embedded within $\mathrm{N}$-doped porous graphitic carbon nanocube/carbon nanotube composite. Chem. Eng. J. 2017, 328, 546-555.

[48] Kong, S. F.; Dai, R. L.; Li, H.; Sun, W. W.; Wang, Y. Microwave hydrothermal synthesis of Ni-based metal-organic frameworks and their derived yolk-shell $\mathrm{NiO}$ for Li-Ion storage and supported ammonia borane for hydrogen desorption. ACS Sustainable Chem. Eng. 2015, 3, 1830-1838.

[49] Ou, X.; Li, J.; Zheng, F. H.; Wu, P.; Pan, Q. C.; Xiong, X. H.; Yang, C. H.; Liu, M. L. In situ X-ray diffraction characterization of $\mathrm{NiSe}_{2}$ as a promising anode material for sodium ion batteries. J. Power
Sources 2017, 343, 483-491.

[50] Zhu, S. H.; Li, Q. D.; Wei, Q. L.; Sun, R. M.; Liu, X. Q.; An, Q. Y.; Mai, L. Q. $\mathrm{NiSe}_{2}$ nanooctahedra as an anode material for high-rate and long-life sodium-ion battery. ACS Appl. Mater. Interfaces 2017, 9, 311-316.

[51] Lu, S. Y; Zhu, T. X.; Li, Z. Y.; Pang, Y. C.; Shi, L.; Ding, S. J.; Gao, G. X. Ordered mesoporous carbon supported $\mathrm{Ni}_{3} \mathrm{~V}_{2} \mathrm{O}_{8}$ composites for lithium-ion batteries with long-term and high-rate performance. J. Mater. Chem. A 2018, 6, 7005-7013.

[52] Zhu, G. Y.; Chen, T.; Wang, L.; Ma, L. B.; Hu, Y.; Chen, R. P.; Wang, Y. R.; Wang, C. X.; Yan, W.; Tie, Z. X. et al. High energy density hybrid lithium-ion capacitor enabled by $\mathrm{Co}_{3} \mathrm{ZnC@N-doped} \mathrm{carbon}$ nanopolyhedra anode and microporous carbon cathode. Energy Storage Mater. 2018, 14, 246-252.

[53] Zhao, W. X.; Guo, C. X.; Li, C. M. Lychee-like FeS $@ \mathrm{FeSe}_{2}$ coreshell microspheres anode in sodium ion batteries for large capacity and ultralong cycle life. J. Mater. Chem. A 2017, 5, 19195-19202.

[54] Fang, G. Z.; Wu, Z. X.; Zhou, J.; Zhu, C. Y.; Cao, X. X.; Lin, T. Q.; Chen, Y. M.; Wang, C.; Pan, A. Q.; Liang, S. Q. Observation of pseudocapacitive effect and fast ion diffusion in bimetallic sulfides as an advanced sodium-ion battery Anode. Adv. Energy Mater. 2018, 8,1703155 .

[55] Fang, Y. J.; Yu, X. Y.; Lou, X. W. Formation of hierarchical $\mathrm{Cu}$-doped $\mathrm{CoSe}_{2}$ microboxes via sequential ion exchange for highperformance sodium-ion batteries. Adv. Mater. 2018, 30, 1706668.

[56] Liu, S. T.; Li, D.; Zhang, G. J.; Sun, D. D.; Zhou, J. S.; Song, H. H. Two-dimensional $\mathrm{NiSe}_{2} / \mathrm{N}$-Rich carbon nanocomposites derived from Ni-hexamine frameworks for superb Na-Ion storage. ACS Appl. Mater. Interfaces 2018, 10, 34193-34201. 